\title{
The early role of CMR in the assessment of cardiomyopathy
}

\author{
Matthew Barrett ${ }^{1,2^{*}}$, Deirdre F Waterhouse ${ }^{2,1}$ \\ From 15th Annual SCMR Scientific Sessions \\ Orlando, FL, USA. 2-5 February 2012
}

\section{Summary}

We performed a one year study to assess the impact of CMR imaging on the management of patients with suspected or confirmed cardiomyopathy.

\section{Background}

Investigation and risk stratification of suspected or confirmed cardiomyopathy traditionally involves correlation between electrocardiographic, echocardiographic and angiographic findings in an appropriate clinical setting. Cardiac Magnetic Resonance (CMR) is the new gold standard in assessment of cardiac structure, function and perfusion, provided in a single study. Aetiology and prognostic factors may be investigated concurrently.

\section{Methods}

This was a single centre, 12-month experience of patients referred for assessment of presumptive cardiomyopathy. Images were provided by a $1.5 \mathrm{~T}$ GE Scanner and were reported by a Level 3 Reporter.

\section{Results}

224 patients (145 male, 79 female) underwent CMR assessment of cardiomyopathy. 177 (79\%) were outpatient referrals.

The primary indications for CMR included

49 (21.9\%) - Arrhythmia

42 (18.8\%) - Abnormal echocardiogram with no cause found

35 (15.6\%) - Cardiac symptoms with normal coronaries

$32(14.3 \%)$ - Screening for family history of CM/SCD

23 (10.3\%) - Abnormal ECG/holter/stress test

$18(8 \%)$ - Follow-up of previously diagnosed CM

17 (7.6\%) - Systemic illness

${ }^{1} \mathrm{SVUH}$, Dublin, Ireland

Full list of author information is available at the end of the article
7 (3.1\%) - ICD insertion

CMR provided sufficient information to confirm or outrule cardiomyopathy in $68.2 \%$ of cases. A new diagnosis of cardiomyopathy was made in $25.4 \%$. CMR also had an important role in ongoing assessment of patients with established diagnosis of cardiomyopathy, with $22.2 \%$ having their previous diagnosis outruled and $27.8 \%$ being recommended for device implantation as a direct result of CMR findings.

Overall in cardiomyopathy assessment, CMR had an impact on management in $50 \%$ of patients, with a therapeutic consequence on $36.2 \%$, including medication changes, angiography and device insertion.

\section{Conclusions}

Patients at all stages of the clinical spectrum of cardiomyopathy, from initial presentation to institution of therapy and long-term follow up may benefit from CMR.

CMR should be implemented early in the diagnostis of suspected cardiomyopathy. Our data demonstrates the significant impact CMR consistently has on confirming diagnosis, guiding therapy and providing accurate prognosis in this patient group.

\section{Funding}

None.

\section{Author details}

${ }^{1}$ SVUH, Dublin, Ireland. ${ }^{2}$ CMR Department, Blackrock Clinic, Dublin, Ireland.

Table 1 Baseline Characteristics

\begin{tabular}{ccc}
\hline Gender & Male -145 & Female -79 \\
Referral Source & OPD -177 & Inpatient -47 \\
BMl & Mean $-26.7 \mathrm{~kg} / \mathrm{m} 2$ & StDev $-4.4 \mathrm{~kg} / \mathrm{m} 2$ \\
Age & Mean -63.4 years & StDev -16.7 years \\
\hline
\end{tabular}




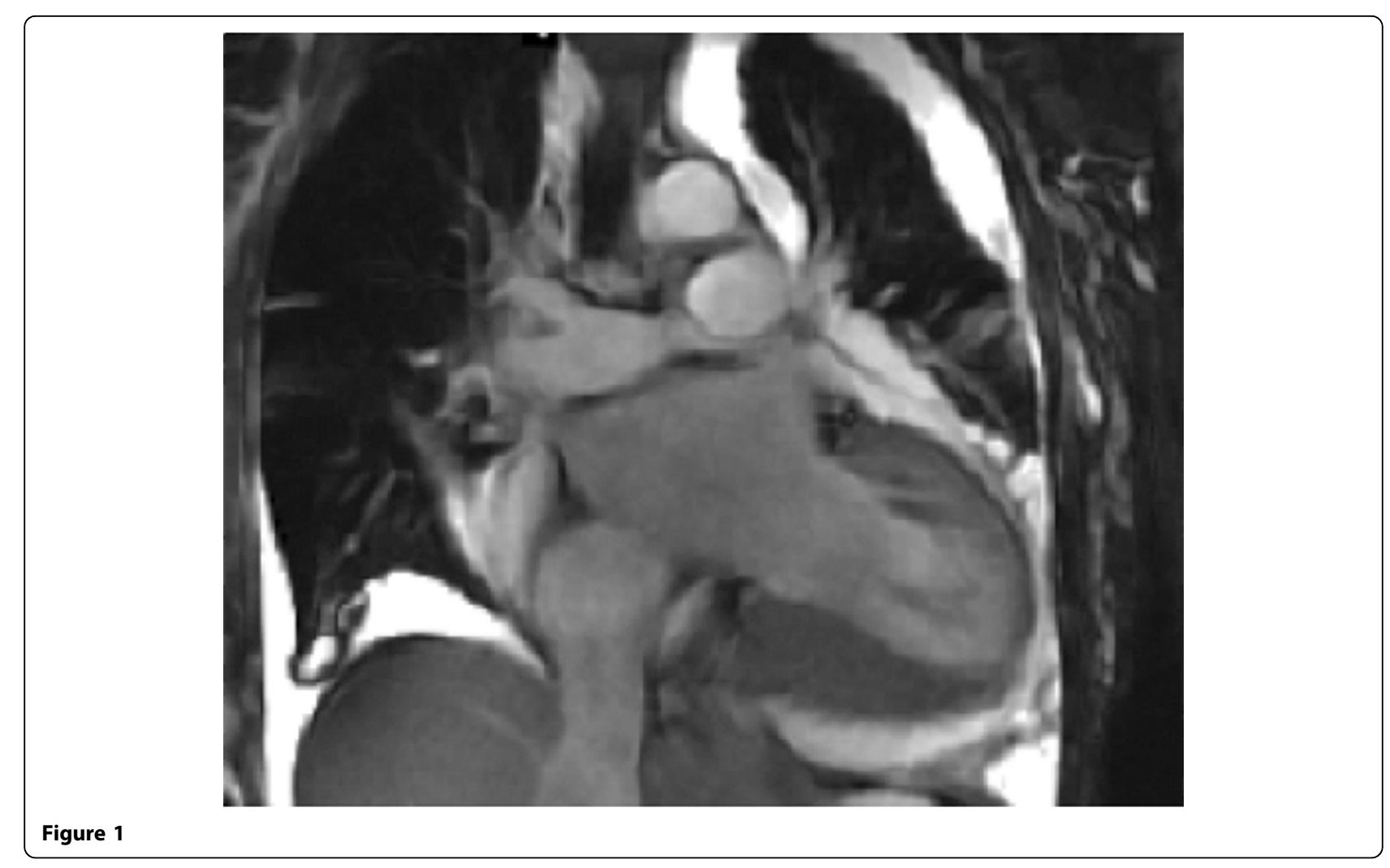

Published: 1 February 2012

doi:10.1186/1532-429X-14-S1-P146

Cite this article as: Barrett and Waterhouse: The early role of CMR in the

assessment of cardiomyopathy. Journal of Cardiovascular Magnetic

Resonance 2012 14(Suppl 1):P146.

Submit your next manuscript to BioMed Central and take full advantage of:

- Convenient online submission

- Thorough peer review

- No space constraints or color figure charges

- Immediate publication on acceptance

- Inclusion in PubMed, CAS, Scopus and Google Scholar

- Research which is freely available for redistribution

Submit your manuscript at www.biomedcentral.com/submit
() Biomed Central 